\title{
Characteristics of Deep Centers Observed in n-GaN Grown by Reactive Molecular Beam Epitaxy
}

Z-Q. Fang ${ }^{1}$, D. C. Look ${ }^{1}$, Wook Kim² ${ }^{2}$, and H. Morkoç ${ }^{3}$

${ }^{1}$ Semiconductor Research Center, Wright State University, Dayton, OH 45435

${ }^{2}$ Center for Solid State Science, Arizona State University, Tempe, AZ 85287-1704

${ }^{3}$ Electrical Engineering and Physics Department, Virginia Commonwealth University, P. O. Box

843072, Richmond, Virginia 23284-3072

\section{ABSTRACT}

Deep centers in Si-doped $n-G a N$ samples grown on sapphire by reactive molecular beam epitaxy, using different ammonia flow rates (AFRs), have been studied by deep level transient spectroscopy. In addition to five electron traps, which were also found in $\mathrm{n}-\mathrm{GaN}$ layers grown by both metalorganic chemical-vapor deposition and hydride vapor-phase epitaxy, two new centers $\mathrm{C}_{1}(0.43-0.48 \mathrm{eV})$ and $\mathrm{E}_{1}(0.25 \mathrm{eV})$ have been observed. $\mathrm{C}_{1}$, whose parameters show strong electric-field effects and anomalous electron capture kinetics, might be associated with dislocations. $E_{1}$, which is very dependent on the AFR, exhibits an activation energy close to that of a center created by electron irradiation and is believed to be a defect complex involving $V_{N}$.

\section{INTRODUCTION}

$\mathrm{GaN}$ and its related ternaries, $\mathrm{AlGaN}$ and $\mathrm{InGaN}$, are being widely developed for blue/uv optical emitters and detectors, and high-temperature/high-power electronics [1]. For both optical and electronic devices, deep centers, which could act as traps and/or recombination centers, are very important, and must be understood. A number of deep centers in $\mathrm{n}-\mathrm{GaN}$, measured by deeplevel transient spectroscopy (DLTS), with activation energies in the range of $0.25-0.87 \mathrm{eV}$ and trap densities in the range of $10^{13}-10^{15} \mathrm{~cm}^{-3}$, have been reported [2-5]. Most of these studies have dealt with n-type GaN grown by either metalorganic chemical-vapor deposition (MOCVD) or hydride vapor-phase epitaxy (HVPE). In a recent DLTS study of deep centers in Si-doped n-GaN grown by reactive molecular beam epitaxy $(\mathrm{RMBE})$, we reported the observation of a trap $\mathrm{E}_{1}$ $(0.21 \mathrm{eV})$ in a particular group of samples (set I), and a dominant trap $\mathrm{C}_{1}(0.44 \mathrm{eV})$ in another group (set II); both centers are peculiar to the RMBE-grown GaN material [6]. In this paper, we present more details on the characteristics of the centers found in samples in set II, i.e., the strong electric-field effect and the unusual capture kinetics of $\mathrm{C}_{1}$ and the relationship between the observation of $\mathrm{E}_{1}$ and the ammonia flow rate (AFR) during RMBE growth. The associations of $\mathrm{C}_{1}$ with dislocations and $\mathrm{E}_{1}$ with nitrogen vacancies will be discussed.

\section{SAMPLES AND EXPERIMENTS}

Four, $\sim 0.5-\mu \mathrm{m}$-thick Si-doped n-GaN samples from set II were used in the present study. The samples were grown at $800{ }^{\circ} \mathrm{C}$ on sapphire by RMBE, employing AFRs of 20, 60 and $73 \mathrm{sccm}$ and keeping the Si flux constant. Schottky barrier diodes (SBDs) were prepared from these materials (for the details see [6]). A Bio-Rad DL4600 system with a 100-mV test signal at $1 \mathrm{MHz}$ was used to take capacitance-voltage $(\mathrm{C}-\mathrm{V})$ and DLTS data. In order to observe the deepest possible centers within a restricted temperature range (up to $400 \mathrm{~K}$ ), the smallest rate 
window $\left(0.8 \mathrm{~s}^{-1}\right)$ in our DLTS system was used. To determine the parameters of the deep-centers, i.e. the activation energy $\mathrm{E}_{\mathrm{T}}$ and capture cross section $\sigma_{\mathrm{T}}$, the DLTS spectra were taken at different rate windows, from 0.8 to $200 \mathrm{~s}^{-1}$. To study the unusual capture kinetics of $\mathrm{C}_{1}$, DLTS spectra were measured, at a fixed bias $(-2.0 \mathrm{~V})$ and a fixed filling pulse height $(+0.5 \mathrm{~V})$, by varying the filling pulse width from 0.2 up to $100 \mathrm{~ms}$.

\section{RESULTS AND DISCUSSION}

The profiles of the electron concentrations for four SBD samples, obtained from 300-K C-V measurements, are basically flat as shown in figure 1 . (The earlier rise observed in the concentration of sample 5964 is evidently due to a smaller $n-G a N$ thickness above the $\mathrm{n}^{+}$-GaN layer). An interesting observation is that the electron concentration in the $\mathrm{n}-\mathrm{GaN}$ layers seems to depend on the AFR; i.e., the lower AFRs for samples 5962 and 5963 result in higher electron concentrations, as compared to those for samples 5961 and 5964. The DLTS spectra for three samples, 5963, 5961, and 5964, with n-GaN layers grown by using AFRs of 20, 60, and $73 \mathrm{sccm}$, respectively, are shown in figure 2a, and a DLTS spectral comparison for samples $5962(20 \mathrm{sccm})$ and $5961(60 \mathrm{sccm})$ is shown in figure $2 \mathrm{~b}$. From the DLTS spectra of the figures, we can observe seven deep centers, labeled as $A_{1}, A, B, C_{1}, C, D$, and $E_{1}$. $A_{1}$, with concentrations of mid- $10^{15}$ to low $-10^{16} \mathrm{~cm}^{-3}$, is a dominant center in RMBE-GaN layers, while $\mathrm{C}_{1}$, with concentrations in the $10^{15}-\mathrm{cm}^{-3}$ range, is also a prominent center in the layers. Two interesting observations are: 1) the peak positions of $A_{1}$ and, especially, $C_{1}$ are found to be sample-dependent: i.e. their peak positions shift to lower temperatures as the electron concentrations in the samples increase; and 2) D, with concentrations in the $10^{14}-\mathrm{cm}^{-3}$ range, is clearly observed in samples 5961 and 5964, grown using higher AFRs, while $\mathrm{E}_{1}$, with concentrations also in the $10^{14}-\mathrm{cm}^{-3}$ range, is only observed in samples 5962 and 5963, grown using lower AFRs (see figure $2 \mathrm{~b}$ for a detailed comparison). The Arrhenius plots of $\mathrm{T}^{2} / \mathrm{e}_{\mathrm{n}}$ for all the deep centers are presented in figure 3. To understand the possible defect nature of $E_{1}$, the Arrhenius plot for the electron-irradiation (EI) induced trap $E$ in $n-G a N$ grown by MOCVD [7] is also presented in the figure. $A_{1}$, with an average $E_{T}=0.89 \mathrm{eV}$ and $\sigma_{\mathrm{T}}=3 \times 10^{-14} \mathrm{~cm}^{2}$, has an energy close to that of

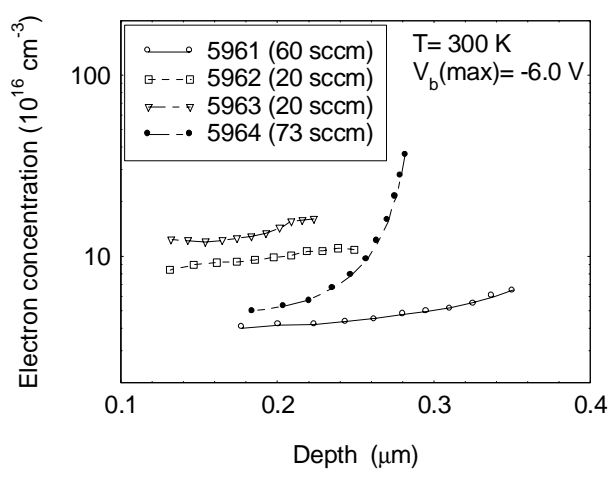

Figure 1. Profiles of electron concentrations for four SBD samples (note the dependence of the electron concentration on AFR).

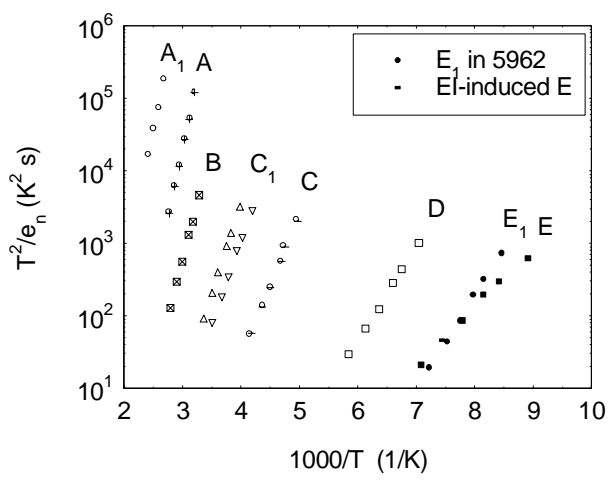

Figure 3. Arrhenius plots of $\mathrm{T}^{2} / \mathrm{e}_{\mathrm{n}}$ for all seven deep centers; also presented is the plot of EI induced trap $\mathrm{E}$ in $\mathrm{n}-\mathrm{GaN}$ grown by MOCVD. 

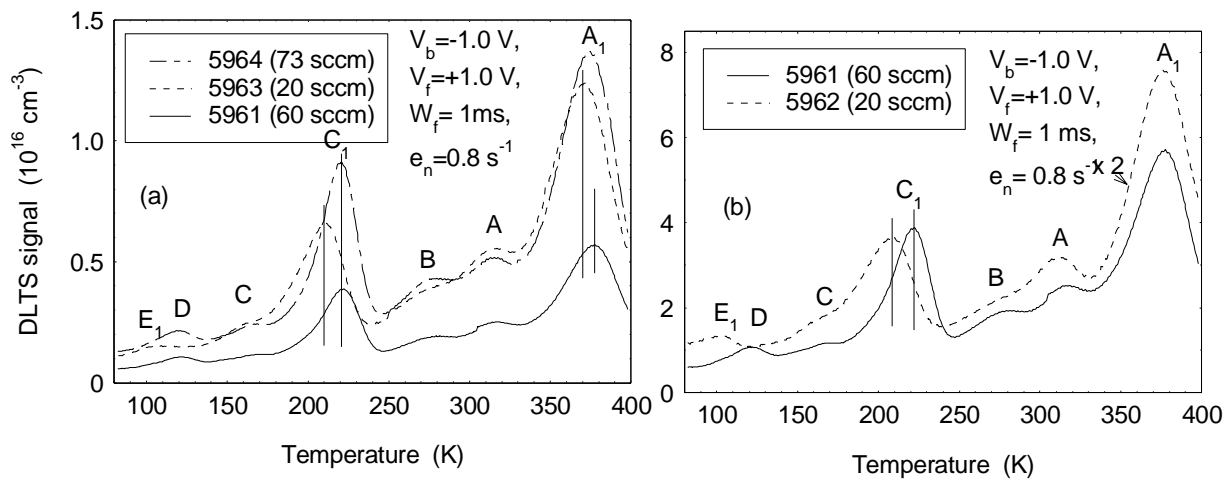

Figure 2. (a) DLTS spectra for three samples, with n-GaN grown using different AFRs, and (b) a DLTS spectral comparison for two samples with different AFRs.

$\mathrm{DLN}_{4}(0.86$ to $0.91 \mathrm{eV})$ [4] and $\mathrm{E} 4(0.88 \mathrm{eV})$ [8], while A, with $\mathrm{E}_{\mathrm{T}}=0.67 \mathrm{eV}$ and $\sigma_{\mathrm{T}}=1 \times 10^{-15}$ $\mathrm{cm}^{2}$, can be compared with $\mathrm{E} 3(0.665 \mathrm{eV})$ [2] and $\mathrm{D} 3(0.67 \mathrm{eV})$ [3]. B, with $\mathrm{E}_{\mathrm{T}}=0.62 \mathrm{eV}$ and $\sigma_{\mathrm{T}}=1.2 \times 10^{-14} \mathrm{~cm}^{2}$, has an energy close to that of E2 $(0.58 \mathrm{eV})[2], \mathrm{D} 2(0.60 \mathrm{eV})[3]$, and $\mathrm{DLN}_{3}$ ( 0.59 to $0.63 \mathrm{eV}$ ) [4]. C, with $\mathrm{E}_{\mathrm{T}}=0.41 \mathrm{eV}$ and $\sigma_{\mathrm{T}}=2.8 \times 10^{-14} \mathrm{~cm}^{2}$, has similarities to the center reported by us in $\mathrm{n}-\mathrm{GaN}$ grown by both MOCVD and HVPE [7]. D, with $\mathrm{E}_{\mathrm{T}}=0.25 \mathrm{eV}$ and $\sigma_{\mathrm{T}}=2.6$ $\mathrm{x} 10^{-15} \mathrm{~cm}^{2}$, is reminiscent of $\mathrm{E} 1(0.26 \mathrm{eV})$ [2] and $\mathrm{DLN}_{1}(0.23$ to $0.25 \mathrm{eV})$ [4]. Thus, we can state that these five deep centers can be observed in $\mathrm{n}-\mathrm{GaN}$ grown by various techniques. However, the concentrations of the centers can be very different, depending on the growth technique. For example, the concentrations of $\mathrm{A}_{1}$ (or E4, $\mathrm{DLN}_{4}$ ) can be very minor (below $10^{13}$ $\mathrm{cm}^{-3}$ ) in MOCVD-GaN [8], in contrast to the high concentrations (above $10^{16} \mathrm{~cm}^{-3}$ ) observed here in RMBE-GaN. On the other hand, $\mathrm{C}_{1}$ and $\mathrm{E}_{1}$ are specific to the $\mathrm{n}-\mathrm{GaN}$ layers grown by RMBE. $\mathrm{C}_{1}$ has a low-field $\mathrm{E}_{\mathrm{T}}$ of 0.43 to $0.48 \mathrm{eV}$ and a $\sigma_{\mathrm{T}}$ of $3 \times 10^{-15}$ to $6.4 \times 10^{-15} \mathrm{~cm}^{2}$, while $\mathrm{E}_{1}$ has an $\mathrm{E}_{\mathrm{T}}$ of $0.25 \mathrm{eV}$ and a $\sigma_{\mathrm{T}}$ of $4.3 \times 10^{-13} \mathrm{~cm}^{2}$, which are close to the values in the EI induced center $\mathrm{E}$ in MOCVD-GaN, with $\mathrm{E}_{\mathrm{T}}=0.18 \mathrm{eV}$ and $\sigma_{\mathrm{T}}=2.5 \times 10^{-15} \mathrm{~cm}^{2}$ [7].

$\mathrm{C}_{1}$ is a very peculiar trap. First, its DLTS peak position is found to be changed not only in different samples, but also in the same sample if $\mathrm{V}_{\mathrm{b}}$ is varied. Typical DLTS spectra measured at different $\mathrm{V}_{\mathrm{b}}$ 's (keeping $\mathrm{V}_{\mathrm{f}}$ fixed at $+1.0 \mathrm{~V}$ ) are shown in figure $4 \mathrm{a}$ and figure $4 \mathrm{~b}$ for samples 5961 $(60 \mathrm{sccm})$ and $5963(20 \mathrm{sccm})$, respectively. From the figures, we find that: 1) $\mathrm{C}_{1}$ is the only peak shifted to lower temperatures as $\mathrm{V}_{\mathrm{b}}$ increases and the total peak shift is found to be more significant in sample 5963 (shift of $\sim 35 \mathrm{~K}$ ) than in sample 5961 (shift of $\sim 10 \mathrm{~K}$ ); and 2) the overall DLTS peak height of $\mathrm{C}_{1}$ drops as $\mathrm{V}_{\mathrm{b}}$ increases, especially in sample 5963. Such a large DLTS peak shift as a function of $\mathrm{V}_{\mathrm{b}}$ implies a very strong electric-field effect on the electron emission from trap $\mathrm{C}_{1}$. Detailed DLTS measurements on sample $5962(20 \mathrm{sccm})$, with a total peak shift of $\sim 30 \mathrm{~K}$, indicate that the apparent $\mathrm{E}_{\mathrm{T}}$ and $\sigma_{\mathrm{T}}$ values are changed from $0.44 \mathrm{eV}$ and $3.0 \times 10^{-15} \mathrm{~cm}^{2}$ to $0.31 \mathrm{eV}$ and $6.4 \times 10^{-17} \mathrm{~cm}^{2}$, respectively, as $\mathrm{V}_{\mathrm{b}}$ is increased from -1.0 to $-4.0 \mathrm{~V}$. Since the peak shift is most likely related to the barrier lowering effect due to a high electric-field, the different shifts found in samples 5961 and 5963 can be interpreted in terms of the different carrier concentrations in the samples $\left(4 \times 10^{16} \mathrm{~cm}^{-3}\right.$ vs $\left.1.2 \times 10^{17} \mathrm{~cm}^{-3}\right)$, which result in different electricfields in the depletion regions. The DLTS peak height drop in $\mathrm{C}_{1}$ and the other DLTS peaks may be related to carrier tunneling or hopping through deep centers at 

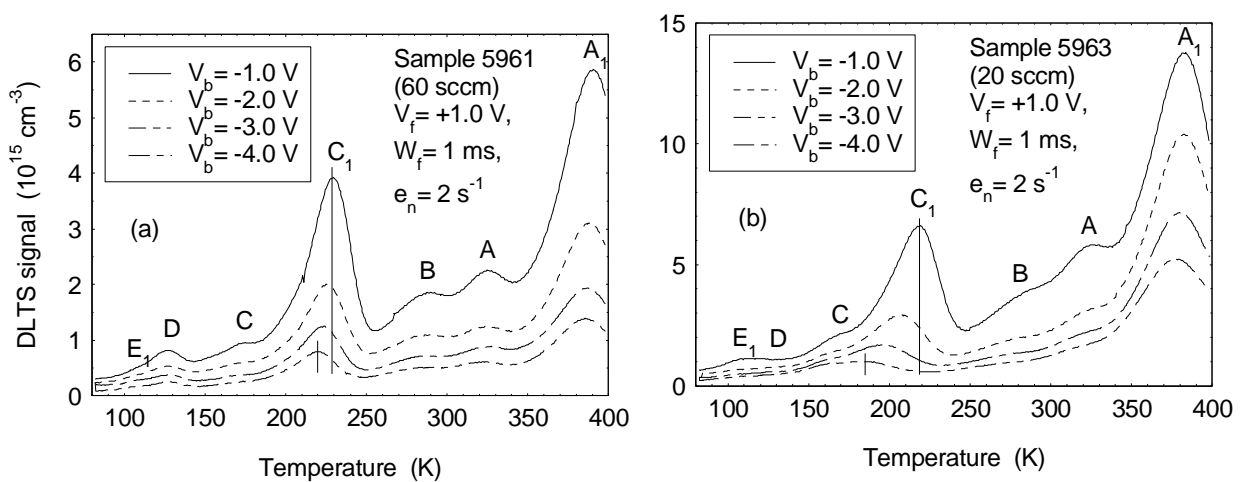

Figure 4. Typical DLTS spectra measured at different $\mathrm{V}_{\mathrm{b}}$ 's for (a) sample 5961 (60 sccm), and (b) sample 5963 (20 sccm).

high electric-field. For centers in the highest field region, this process could lead to a high emission rate, which would not be seen by the DLTS sampling mechanism. We checked the reverse I-V characteristics of the SBD samples used in the study and found a strong electric-field dependence of the reverse leakage currents (so-called soft breakdown characteristic), which is typical for p-n junctions made on GaN-based materials grown on sapphire and believed to be caused by carrier tunneling or hopping through the defect states associated with the omnipresent threading dislocations in the materials $[9,10]$.

Figure 5. Typical DLTS spectra measured at different $\mathrm{V}_{\mathrm{f}}$ 's for sample 5964.

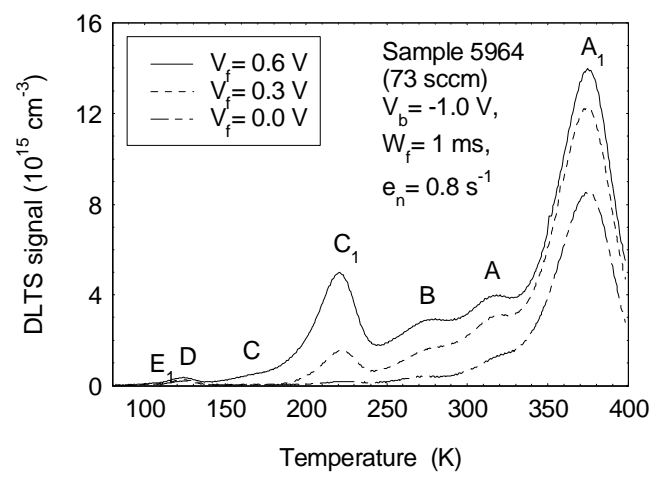

Another distinguishing feature of $\mathrm{C}_{1}$ is that it is found only in the top region of the $\mathrm{n}-\mathrm{GaN}$ layers. Typical DLTS spectra measured at different $\mathrm{V}_{\mathrm{f}}$ 's (keeping $\mathrm{V}_{\mathrm{b}}$ fixed at $-1.0 \mathrm{~V}$ ) for sample 5964 are shown in figure 5. From the figure, we see that the peak height of $\mathrm{C}_{1}$ precipitously drops as $V_{\mathrm{f}}$ decreases from 0.6 to $0 \mathrm{~V}$, resulting in nearly no observation of $\mathrm{C}_{1}$ in the deeper region of the $\mathrm{n}-\mathrm{GaN}$ layer, which is in contrast with the observation of $\mathrm{A}_{1}$ in the whole layer. A final feature of $C_{1}$ is the appearance of very unusual electron capture kinetics; i.e., the DLTS peak height of $C_{1}$ versus $\mathrm{W}_{\mathrm{f}}$ does not show saturation when $\mathrm{W}_{\mathrm{f}}$ is increased from 0.2 up to $100 \mathrm{~ms}$, as pictured in figure 6 for three different samples. From the figure, we see that the DLTS signals show a logarithmic dependence on the filling pulse width, $\mathrm{W}_{\mathrm{f}}$. Such a dependence was experimentally observed for dislocation-related deep centers in plastically deformed Si [11] and 
Figure 6. DLTS signal of $\mathrm{C}_{1}$ versus filling pulse width $\left(\mathrm{W}_{\mathrm{f}}\right)$ for three samples.

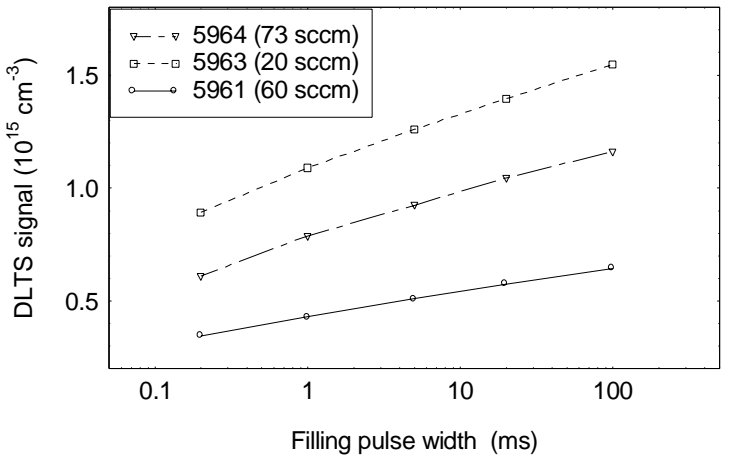

GaAs [12], and explained in terms of a barrier model of electron capture via dislocations [13]. This model assumes that the electron capture rate is limited by a time-dependent Coulomb barrier, with a height proportional to the number of electrons already trapped. Such a situation occurs when the traps are not randomly distributed throughout the crystal but are arranged along lines (so-called "line defects"). Recently, Auret et al. reported a deep center, ER5 ( $\mathrm{E}_{\mathrm{C}}-0.95 \mathrm{eV}$ ), which was introduced by an irradiation of 5.4-MeV He ions, and found that the electron capture kinetics of ER5 were similar to those of a line defect [14]. In our case, the line-defect-like trap occurs in as-grown material, which gives good evidence that $C_{1}$ is associated with dislocations. Note that thick MOCVD- and HVPE-GaN layers typically have dislocation densities in the $10^{8}-\mathrm{cm}^{-2}$ range, while thin MBE-GaN layers usually have higher dislocation densities, by one to two orders of magnitude. That might be the reason why we can observe $C_{1}$ only in thin RMBE-GaN layers, but not in MOCVD and HVPE layers.

$\mathrm{E}_{1}$, with a trap concentration in the mid $-10^{15} \mathrm{~cm}^{-3}$ range, was first observed in the RMBE-GaN samples in set I [6]. Here, in the RMBE samples of set II, we also observe $E_{1}$, but with lower trap concentrations (in the $10^{14} \mathrm{~cm}^{-3}$ range), and only in those samples (5962 and 5963) grown with lower AFRs. The higher concentrations of $\mathrm{E}_{1}$ in the samples of set I might be related to the undoped SI GaN layer under the $\mathrm{n}-\mathrm{GaN}$ layer, since we have found a significant thermally stimulated current trap at low temperatures in RMBE-grown SI-GaN, with an approximate activation energy of $0.17 \mathrm{eV}$ [15]. Note that this energy is also close to that of the EI-induced trap $\mathrm{E}$, thought to be related to an $\mathrm{N}$ vacancy. In this light, the variation of $\mathrm{E}_{1}$ with AFR can be understood in terms of the existence of $\mathrm{V}_{\mathrm{N}}$-related defects; i.e., the lower AFR would result in a higher concentration of $\mathrm{V}_{\mathrm{N}}$ and vice versa. Also, the observed dependence of carrier concentration with AFR (figure 1) may involve $\mathrm{V}_{\mathrm{N}}$-related donors, or impurity donors, such as oxygen, on the $\mathrm{N}$ site. Note that Si donors, on the Ga site, would be expected to increase at higher AFR. The EIinduced trap E most likely has a Frenkel pair $\left(\mathrm{V}_{\mathrm{N}}-\mathrm{N}_{\mathrm{I}}\right)$ nature and anneals out at about $300{ }^{\circ} \mathrm{C}[16]$. Thus, the trap $\mathrm{E}_{1}$, which is stable at the growth temperatures of $750-800{ }^{\circ} \mathrm{C}$, cannot be identical to $\mathrm{E}$, but is probably a defect complex involving $\mathrm{V}_{\mathrm{N}}$.

\section{CONCLUSIONS}

Deep centers in Si-doped n-GaN samples grown on sapphire by RMBE, using different AFRs, have been studied by DLTS over a temperature range of 80 to $400 \mathrm{~K}$. In addition to 
DLTS centers $\mathrm{A}_{1}(0.89 \mathrm{eV}), \mathrm{A}(0.67 \mathrm{eV}), \mathrm{B}(0.62 \mathrm{eV}), \mathrm{C}(0.45 \mathrm{eV})$ and $\mathrm{D}(0.24 \mathrm{eV})$, which are commonly observed in MOCVD- and HVPE-GaN, two new centers $\mathrm{C}_{1}$ and $\mathrm{E}_{1}$ are found in RMBE-GaN. $\mathrm{C}_{1}$, with a low-field activation energy of 0.43 to $0.48 \mathrm{eV}$, depending on the carrier concentration, shows strong electric field effects. Its unusual electron capture kinetics suggests that it might be related to a dislocation. $\mathrm{E}_{1}$, with an activation energy of $0.25 \mathrm{eV}$, shows a close connection with the AFR and is believed to be a defect complex involving the nitrogen vacancy.

\section{ACKNOWLEDGMENTS}

The work of Z-Q.F. and D.C.L. was supported by U.S. Air Force Contract No. F33615-95-C1619. Part of the work was performed at the Air Force Research Laboratory, Wright-Patterson Air Force Base, OH. Also, partial support was received from the Air Force Office of Scientific Research. The research at VCU is funded by AFOSR, ONR, and NSF.

\section{REFERENCES}

1. S. N. Mohammand, A. A. Salvador, and H. Morkoç, Proc. IEEE 83, 1306 (1995).

2. P. Hacke, T. Detchprohm, K. Hiramatsu, N. Sawaki, K. Tadatomo, and K. Miyake, J. Appl. Phys. 76, 304 (1994).

3. D. Haase, M. Schmid, W. Kurner, A. Dornen, V. Harle, F. Scholz, M. Burkard, and H. Schweizer, Appl. Phys. Lett. 69, 2525 (1996).

4. W. K. Gotz, J. Walker, L. T. Romano, N. M. Johnson, and R. J. Molnar, Mater. Res. Soc. Symp. Proc. 449, 525 (1997).

5. C. D. Wang, L. S. Yu, S. S. Lau, E. T. Yu, W. Kim, A. E. Botchkarev, and H. Morkoç, Appl. Phys. Lett. 72, 1211 (1998).

6. Z-Q. Fang, D. C. Look, W. Kim, Z. Fan, A. Botchkarev, and H. Morkoç, Appl. Phys. Lett. 72, 2277 (1998).

7. Z-Q. Fang, J. W. Hemsky, D. C. Look, M. P. Mack, R. J. Molnar, and G. D. Via, Mater. Res. Soc. Symp. Proc. 482, 881 (1998).

8. P. Hacke, H. Okushi, T. Kuroda, T. Detchprohm, K. Hiramatsu, and N. Sawaki, J. Crystal Growth, 189/190, 541 (1998).

9. D. V. Kuksenkov, H. Temkin, A. Osinsky, R. Gaska, and M. A. Khan, Appl. Phys. Lett. 72, 1365 (1998).

10. P. G. Eliseev, P. Perlin, J. Furioli, P. Sartori, J. Mu, and M. Osinski, J. Electron. Mater. 26, 311 (1997)

11. V. V. Kveder, Yu. A. Osipyan, W. Schroter, and G. Zoth, Phys. Status Solidi A 72, 701 (1982).

12. T. Wosinski, J. Appl. Phys. 65, 1566 (1989).

13. T. Figielski, Solid State Electron. 21, 1403 (1978).

14. F. D. Auret, S.A. Goodman, F. K. Koschnick, J-M. Spaeth, B. Beaumont, and P. Gibart, Appl. Phys. Lett. 73, 3745 (1998).

15. D. C. Look, Z-Q. Fang, W. Kim, O. Aktas, A. Botchkarev, A. Salvador, and H. Morkoç, Appl. Phys. Lett. 68, 3775 (1996).

16. D. C. Look, D. C. Reynolds, J. W. Hemsky, J. R. Sizelove, R. L. Jones, and R. J. Molnar, Phys. Rev. Lett. 79, 2273 (1997). 